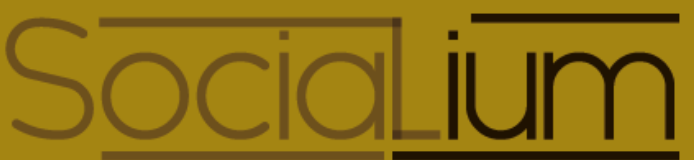

Revista Científica de Ciencias Sociales

e-ISSN: 2706-6053

\title{
Presidencialismo y política peruana
}

Presidentialism and Peruvian politics

Luis Vicente Manrique Álvarezl

RECIBIDO: ENERO 82019

ACEPTADO: JUNIO 32019

1 Sociólogo, Magíster en Sociología, docente principal de la Universidad Nacional del Centro del Perú, Imanrique@uncp.edu.pe, https://orcid.org/0000-0002-3236-0372

Socialium revista científica de Ciencias Sociales, Vol 3 - No. 2 julio - diciembre 2019, Pag 11-20

DOI https://doi.org/10.31876/sl.v2i1.46

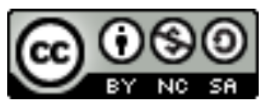




\section{Resumen}

Este documento, resultado de un trabajo de investigación sobre el presidencialismo y la política peruana, propone que en el vértice de nuestra política, se reproducen arcaísmos autoritarios de diversos signos y secuelas, a instancias del omnímodo poder que se enhebra en torno a los alcances legales y subjetivos de nuestra democracia presidencialista. Poder acrecentado a propósito de la débil institucionalidad republicana y democrática, a la búsqueda del "líder salvador" y al interesado sometimiento de poderes paritarios. Así, el derrotero presidencial se sustrae de los cauces legales hasta bordear los límites preocupantes del autoritarismo. Esta postura puede verse replicada por más de una autoridad política subnacional. Por ello, nos planteamos el objetivo de establecer la influencia del presidencialismo en la política peruana, así como en las autoridades políticas subnacionales. La metódica asume la rigurosidad del método científico y su variante histórico-cualitativa. Por su parte, los resultados constatan la tesis de Juan Linz, que considera al presidencialismo como menos favorable que el parlamentarismo para los fines democráticos. Aquel requiere de efectiva estabilidad institucional, política y jurídica. Concluimos que la política nuestra arroja saldos negativos, pues la arraigada verticalidad, ahora presidencial, tiende a estancarla, a desvirtuar la ciudadanía y a deformar sus instituciones.

Palabras clave: presidencialismo, parlamentarismo, política, arcaísmo, autoritarismo, democracia, república.

\section{Abstract}

This document, the result of a research on presidentialism and Peruvian politics, proposes that at the apex of our politics, authoritarian archaisms of various signs and sequels are reproduced, at the behest of the omnipotent power that is threaded around the legal and subjective scope of our presidential democracy. Power increased on the basis of a weak democratic and republican institutionality, in search of the "savior leader" and the interested submission of joint powers. Thus, the presidential course is removed from the legal channels to border the worrisome limits of authoritarianism. This position can be replicated by more than one subnational political authority. For this reason, we have set ourselves the objective of establishing the influence of presidentialism on Peruvian politics, as well as on subnational political authorities. The methodology assumes the rigor of the scientific method and its historical-qualitative variant. For their part, the results confirm the thesis of Juan Linz, which considers presidentialism as less favorable than parliamentarism for democratic purposes. The first one requires effective institutional, political and legal stability. We conclude that our politics yield negative balances, because the entrenched verticality, now presidential, tends to stagnate them, to distort citizenship and to deform our institutions.

Keywords: presidentialism, parliamentarism, politics, archaism, authoritarianism, democracy, republic. 


\section{Introducción}

En el contexto actual, ningún fenómeno social y político podría explicarse de manera extendida al margen de los alcances de la globalización. Es en ese marco que el constructo de la modernidad (al que no terminamos de ingresar), advierte que sus instituciones y ethos culturales vienen sufriendo serias modificaciones. Empieza a desmoronarse la edificación secular de las centurias anteriores y, en su lugar, atisban los contornos de una nueva sociedad que más de una propuesta teórica entiende como una naciente civilización.

En el interregno entre uno y otro siglo, entre una, al parecer agotada civilización, y otra nueva, adviene el desorden, la pérdida de orientación, la alteración de las instituciones establecidas.

En ese mismo interregno, la debilidad de nuestra institucionalidad republicana, nacional y democrática se acentúa. La impronta del caudillo decimonónico, la presencia del líder providencial del siglo XX, se confunde con el autoritarismo y neocaciquismo del interior del país, hechos que se reflejan en la conducción de los gobiernos subnacionales, en pleno siglo XXI.

En ese sentido, la política y los liderazgos, en nuestra historia republicana, han hecho de nuestro Estado un organismo ajeno a la soberanía, que se muestra como un ente sometido al poder financiero y demás poderes fácticos; pero, al mismo tiempo, se muestra distante y por encima de las instituciones, la ciudadanía y el propio orden jurídico.

En ese espacio se fortalecen, además, los extremos de un mismo fenómeno. De un lado, la personalización del poder hasta límites delirantes; de otro, la relatividad del concepto ciudadano y la independencia del mismo. La adulación y el cretinismo se constituyen en moneda corriente en nuestro país.

Esta es una vieja como prolongada historia. Cuando el expresidente Augusto B. Leguía sentía los embates de los opositores, llegó a decir en un alegato que "si se cree que el Perú puede progresar sin mí, en buena hora. Pero lo esencial es que ese progreso no se detenga". Leguía, envanecido, dudaba que el Perú pudiera avanzar sin su personal concurso.

Más contemporáneamente, con Alan García, la gestión gubernamental se personaliza al extremo. Como Pease (2010) refiere, en 1985, la victoria fue efectivamente del APRA, pero se consideró entonces, como en su segunda gestión, que el partido no era la organización de gobierno. El hecho es que se personaliza no solo la victoria, sino el propio acto de gobernar. Tal personalización no solo es un rasgo de la postura tradicional y mesiánica de nuestros líderes, sino también de los fueros que permite la llamada democracia presidencialista instalada en el Perú. 
En la región Junín ocurre otro tanto. En los últimos meses del gobierno regional anterior, encabezado por Angel Unchupaico, los partidarios y funcionarios de su gestión organizaron una masiva "marcha ciudadana de agradecimiento" por las obras que "personal y generosamente" habría impulsado el gobernador regional.

Así, nos planteamos el objetivo de establecer la influencia del presidencialismo en la política peruana y en el desempeño y prácticas de las autoridades subnacionales. Ambas instancias, la política nacional y regional, mantienen una vertical relación. Ahí el punto de partida que facilitaría el entendimiento de los tortuosos caminos de la política pervana.

La conjetura que guía el trabajo mantiene la idea de que los requiebros democráticos no parten precisamente de los espacios populares, sino que se desprenden, más bien, de instancias superiores: de la propia Constitución Política y de los humores afincados en Palacio de Gobierno.

Los resultados fueron confrontados con las diversas propuestas teóricas que explican los desórdenes políticos (caudillismo, providencialismo, caciquismo, cultura mesiánica, etc.). Sin embargo, el vértice aludido, el presidencialista, concentra y bifurca desde la gestión cotidiana los efectos de sus propias deformaciones.

Este, debemos decirlo, no es un trabajo acabado. Expresa, sí, intentos de aproximación al problema, aún con las limitaciones que pueda exhibir.

\section{Materiales y métodos}

La metódica considerada se enmarca dentro de la rigurosidad del método científico. En ese orden, recurrimos al método cualitativo e histórico.

De otro lado, hemos considerado materiales diversos, entre tecnológicos, cibernéticos y tradicionales. Destacan revisiones bibliográficas para su utilización en los fundamentos teóricos, así como una intensa búsqueda hemerográfica y periodística, principalmente esta última, para la confrontación de resultados.

La riqueza de la investigación podría desprenderse del acopio teórico y su entrelazamiento con las manifestaciones de nuestros informados entrevistados (especialistas, académicos y periodistas, básicamente).

\section{Resultados}

Con Juan Linz se considera que el presidencialismo es menos favorable que el parlamentarismo para los objetivos democráticos, pues aquel requiere (como ocurre 
en los EE.UU., en base a sus sólidas instituciones y sistemas políticos bipartidistas) de reconocida estabilidad jurídica, política e institucional.

Este, el parlamentarismo, podría fortalecer la democracia al contar con una mayor capacidad de enmiendas al poder en funciones y, de requerirse, cambiar a los propios responsables del gobierno, por él designados. Asimismo, el parlamentarismo conduce a un mayor entendimiento de las partes que pugnan y acuerdan en el parlamento y exige un mayor compromiso con la democracia. Ese es el caso de las democracias parlamentarias europeas (Francia, p. ej.).

En este caso, no se generan inútiles discusiones sobre la legitimidad popular, como ocurre en nuestro país. Ambos son representativos y gozan de la misma legitimidad.

Sin embargo, Mainwaring y Shugart (1994) encuentran que lo propuesto por Linz, siendo importante, tendría serias dificultades en contextos como el nuestro:

El presidencialismo también parece ser viable con partidos que son por lo menos algo disciplinados, y resulta especialmente problemático con sistemas multipartidistas muy fragmentados y con elecciones parlamentarias que ocurren con más frecuencia que las elecciones presidenciales. Finalmente, planteamos que cambiar del presidencialismo al parlamentarismo podría exacerbar problemas de gobernabilidad en países con partidos muy indisciplinados (p. 255)

Nuestro caso, de democracia presidencialista, ofrece etapas de desencuentro ejecutivo-legislativo, a propósito de mayorías parlamentarias. Esta disparidad de fuerzas y desencuentros ha conducido a sendos golpes de Estado. Así ocurrió durante los gobiernos del depuesto José Luis Bustamante y Rivero (1945-1948) con predominio congresal del Partido Aprista; y lo mismo pasó 20 años después, en el primer gobierno de Fernando Belaunde Terry. El Congreso de entonces contaba con mayoría opositora: APRA y UNO. Belaunde Terry terminó defenestrado del poder, a manos de las FF. AA., quienes se sostuvieron en el gobierno durante 12 largos años.

En América Latina y en el Perú, la principal traba del régimen presidencialista, como grafica la historia, estriba en que no siempre se alcanza mayoría congresal. Teniendo la mayoría opositora condiciones para marcar la agenda político-nacional y controlar al ejecutivo. En los predios nacionales, hemos asistido a la renuncia del presidente Kuczynski a fin de evitar su vacancia por corrupción. Y, en estos días, con su sucesor, el Ing. Martín Vizcarra, vuelve a tocarse el tema de vacancia ante la presión congresal.

Valenzuela (1996) analiza un aspecto clave para el funcionamiento de un sistema presidencialista:

El presidencialismo solo ha tenido éxito en los Estados Unidos. Muchos factores han contribuido a consolidar en ese país un régimen basado en la separación de poderes, incluyendo el desarrollo de una Corte Suprema como árbitro entre los otros 
dos poderes, la firme tradición del control civil sobre el militar, y la práctica del federalismo (que por generaciones centralizó el poder en los Estados en vez de hacerlo a nivel nacional). A pesar de estos factores, es improbable que el presidencialismo hubiera tenido éxito en Estado Unidos si no hubiera sido por algo que no previeron los fundadores de los Estados Unidos, a saber, el desarrollo de partidos políticos distintos, organizados en un sistema bipartidario. (p. 18)

Hemos señalado que el sistema presidencialista, al contar con facultades extendidas (representa a la nación, designa ministros, impulsa las políticas públicas y sociales, comanda las Fuerzas Armadas y Policiales, elabora el presupuesto de la república, dirige la política exterior, entre otras responsabilidades) y controles difusos, afecta el propio ejercicio presidencial.

De otro lado, es perversamente usual que el presidente considere, al vencer en los comicios electorales, que lo ha ganado todo y que se encuentra por encima del Congreso de la República. Esa particularidad es replicada por los actores o responsables de los gobiernos subnacionales. En ambos casos, regionales y municipales, la ley los faculta a gobernar con sus propios equipos partidarios y asesorías, más allá de la frágil fiscalización de consejeros regionales y regidores, respectivamente.

Al respecto, Pease (2010) afirma:

Inevitablemente deberemos regresar a los aspectos institucionales y preguntarnos por qué el Presidente de la República tiene tanto poder en el parlamento y en el poder judicial y tendremos que regresar a la cultura política generada en el siglo XX, al pánico que causa la posibilidad de que funcione la separación de poderes que ha llevado a que se manipulen las instituciones para que los parlamentarios dependan del presidente. (p. 14)

Otros hechos consustanciales, a propósito de los nuevos ejes de poder mundial, de la importancia relativa de la política, vienen cuestionando la situación de la democracia y la importancia decisoria del ciudadano.

Estos hechos estarían fortaleciendo en el mundo las posturas más conservadoras y xenófobas. Estos mismos hechos vienen generando el peligroso estancamiento de esa democracia.

La vieja Europa, caracterizada en décadas anteriores por su apego a los valores democráticos, ahora sufre peligrosos giros hacia el conservadurismo. Sánchez (2018) escribió sobre el particular:

La crisis de los refugiados está en el meollo de la pugna política e ideología actual. En Occidente, particularmente en la Unión Europea. El giro hacia la derecha es tan marcado que hasta una canciller conservadora de centro derecha como Angela Merkel parece ubicarse en la izquierda del espectro partidario. 
En América Latina ocurre algo similar, la democracia, a la luz del nuevo contexto, tiende a debilitarse. En los hechos, y bajo la presión empresarial, los derechos laborales se constriñen con el pretexto de la flexibilidad. Gustavo Gorriti (2017), destacado periodista, escribía:

En América Latina, donde sucedió a las últimas dictaduras militares del siglo XX con una expectativa de progreso y pertinencia, la democracia pasa por una evidente depresión. De acuerdo con el informe que encabeza el latinobarómetro de este año, mientras la economía latinoamericana crece, la democracia continúa su declive. Hay "bajas sistemáticas del apoyo y la satisfacción de la democracia (...) los gobiernos sufren la misma suerte, cada año los latinoamericanos los aprueban menos. Lo que hoy en el promedio antes era el mínimo". (párr. 9-10)

La relatividad de la importancia de la democracia debilita sus instituciones y hace que en el horizonte, aparezca, fortalecida, la figura preponderante del líder o caudillo. Esta postura permite que el presidente o la autoridad similar vean acentuadas sus cuotas de poder. Ello afecta aún más la subjetividad de la ciudadanía.

Lechner (2015), estudioso de la política y la subjetividad, explica:

Las ideas de progreso técnico o de emancipación humana representaban un horizonte que acotaba el devenir; un horizonte de futuro que se representaba simultáneamente; un horizonte de sentido en nombre del cual se interpretaba y justificaba el presente. En cambio, hoy día, la noción misma de futuro se diluye. Existen proyecciones del presente (planes de inversión, cálculo de riesgos, etc.), pero no una imagen del futuro. Ello toca directamente a la concepción moderna de la política, entendida como construcción deliberada del futuro. (p. 73)

Como se puede inferir, el contexto actual no se vería favorable para el fortalecimiento de la democracia, sus instituciones y el liderazgo social, propios de una sociedad moderna. En su lugar, se impone el liderazgo de carácter personal que, en las democracias presidencialistas, convierten al gobernante en una entidad incuestionable.

En nuestro país, entonces, que apuesta por el presidencialismo, la democracia convive con formas de poder y quehacer político arcaicos.

Es que con la figura del presidencialismo, se tiende a establecer una especie de "ganador único", en disputa con el propio Congreso por la principal legitimidad, aun cuando ambos poderes, ejecutivo y parlamento, tengan el mismo origen democrático (ambos, Ejecutivo y Legislativo son elegidos por el voto eleccionario).

La nuestra es una democracia presidencialista, con instituciones republicanas sometidas, con un sistema de partidos sin mayor representatividad y funcionamiento 
nacional que fortalece aquel presidencialismo, con los efectos diversos de autoritarismos, patrimonialismos y prebendismos.

No solo ello. Degregori (2001) escribió sobre "la década de la antipolítica", impulsada en los años 90, con el fin de profundizar, desde las esferas más altas del poder y la prensa, la crisis de partidos y encumbrar la figura presidencial.En ese contexto, se generan nuevas disonancias. Ahora habría nuevos conspiradores que atentan contra nuestra frágil democracia. Explica Neira (2012):

Antes complotaban las oligarquías. Hoy en día, los políticos venidos de las capas emergentes, los recién llegados, ya no desde las antiguas clases medias sino de los nuevos ricos, se hallan dispuestos a establecer nuevos despotismos, disfrazados de legítimos. Establecerse en el poder para siempre no se hace más con botas sino con votos. (p. 17)

Un nuevo actor político, que refuerza la postura vertical en el ejercicio político, es el empresario que ingresa a la política. Todo indica que estos reproducen sus estilos de dirección empresarial en el quehacer político. No solo eso, al carecer de experiencias políticas y prácticas democráticas partidarias, apelan al concurso rentado de los operadores.

Zavaleta (2014) explica que "los empresarios devenidos en políticos han adoptado una estrategia discursiva característica: trasladar su experiencia de gestión privada a la gestión pública, y una táctica práctica: el reparto de bienes materiales como parte central de sus campañas" (p. 104).

De otro lado, el personalismo presidencial se traslada a los diversos liderazgos, sesgando la actuación política hacia fines particulares. Vergara (2013), en el caso del partido de la estrella, afirma:

Alan García ha manejado su partido a caballo entre el desgano y el rechazo. Ha carecido de grandeza para formar cuadros jóvenes que pudiesen darle aire al partido. Más bien, se satisface levantando y desinflando liderazgos, enemistando a unos y otros $y$, sobre todo, se felicita de gobernar con sus nuevos amigos ricos, reaccionarios, poderosos y blancos. (p. 192)

\section{Discusión}

¿Qué origina, en el caso peruano, la potenciación del sistema presidencialista? Diversos factores. Resaltemos los considerados más relevantes.

Alberto Flores Galindo, en su La tradición autoritaria (1999), afirmó que en el Perú el éxito de la política solo es posible bajo la figura del caudillo. Con ello puede confirmarse que la política, más que programática, teórica e institucional, es 
antropomorfa. Esta herencia, siempre presente, refuerza y traslada a los tiempos actuales la figura del caudillo.

Así, las preferencias políticas permiten confluir viejas herencias coloniales e incluso religiosas: la búsqueda del hombre que, por sí solo, resuelva las dificultades. Así, la esperanza y el sentido de protección se encarnan en la figura política considerada salvadora (la figura redentora se traslada al ejercicio político actual).

El Dr. Américo Meza Salcedo, profesor principal en la Universidad Nacional del Centro del Perú (UNCP), explica que "la cultura poscolonial encierra un fuerte contenido subalterno. Los siglos de dominación colonial española hubieron de dejar secuelas negativas en la formación ciudadana, ya en la república, ya en el propio siglo XXI."

Asimismo, entrada la república, ese rezago de dominación cultural se acentúa, a propósito de la aparición hacendaria y gamonal. Tal dominación, que restó el reconocimiento de derechos hasta el siglo XX, reflejo del predominio oligárquico, extendieron los contornos de una sociedad signada por la existencia de ciudadanos reales e imaginarios, como explica la sociología peruana (López, 1997).

Ese sentido, considerando los aportes de Meza Salcedo, se permite tomar al presidente de la República como el sucesor del rey, o del profeta que habrá de velar por el bienestar de todos. Así, la institucionalidad de las sociedades modernas tiende, en nuestro país, a debilitarse hasta bordes preocupantes.

De otro lado, se advierte la tendencia de los otros poderes a "voluntariamente" subordinarse al poder central. Se establece, en los hechos, una suerte de autoritarismo o despotismo presidencial. Un pretexto a ese allanamiento es la anual asignación presupuestal o las llamadas ampliaciones presupuestales que dependerían del gobernante y del propio ministro de Economía en funciones.

El Dr. Wild Cerrón León, profesor en la UNCP, refiere:

Esa relación o sometimiento visto en los centros de poder capitalinos, también se observan al interior del país. En la región Junín puede verse de cómo se allanan los consejeros regionales o los regidores ante la autoridad a cambio de privilegios personales o familiares. Otro tema es el de la prensa. Aquí se establecen relaciones de amor $u$ odio, dependiendo de los favores concedidos o exigidos.

Otro hecho que estaría reforzando el encubrimiento de la autoridad tiene que ver con el acercamiento empresarial. Como se sabe, la inversión pública, al interior del país, es considerable, de manera que los éxitos empresariales en la construcción dependen de la ligazón que pueda establecerse con la autoridad subnacional. Ello daría lugar a lo que se conoce como mercantilismo o prácticas cortesanas.

El comunicador social Cristóbal Valdivia Ramírez, acucioso observador del acontecer regional, declara: 
Es alarmante lo que viene ocurriendo en la región. Podemos apreciar el trato concedido por los medios periodísticos con la autoridad, como el preferente trato de algunos empresarios al gobernador o alcaldes. Cuando éstos son entrevistados en nuestros programas se declaran adictos a la autoridad o severos críticos de acuerdo a cómo les va con ellos.

Así entonces, puede colegirse que la preponderancia legal, que favorece al presidente en funciones, es imitada por la autoridad subnacional y por las personas cercanas a ellas: seguidores, funcionarios, periodistas y empresarios.

\section{Referencias bibliográficas}

Degregori, C. I. (2001). La década de la antipolítica. Lima: IEP.

Flores, A. (1999). La tradición autoritaria. Violencia y Democracia en el Perú. Lima: Sur Casa de Estudio del Socialismo.

Gorriti, G. (14 de diciembre de 2017). Democracias en peligro. Caretas. Recuperado de https://idl-reporteros.pe/columna-de-reporteros-321/

Lechner, N. (2015). Política y subjetividad. México D. F.: Fondo de Cultura Económica.

López, S. (1997). Ciudadanos reales e imaginarios: concepciones, desarrollo y mapa de la ciudadanía en el Perú. Lima: Instituto de Diálogo y Propuestas.

Mainwaring, S., y Shugart, M. (1994). Juan J. Linz: presidencialismo y democracia. Una revisión crítica. Desarrollo Económico, 34(135), 397-418. Recuperado de https://www.google.com/url? sa=t\&rct=j\& $q=\&$ esrc $=s \&$ source $=w e b \& c d=1 \& v$ ed=2ahUKEwj_urDygKfkAhWCwVkKHVUyBjkQFjAAegQIARAB\&url=https\%3A \%2F\%2Fforointernacional.colmex.mx\%2Findex.php\%2Ffi\%2Farticle\%2Fdownl oad\%2F1339\%2F1329\&usg=AOvVaw0ypKVDj4OlqzknVKv-Cibc

Neira, H. (2012). ¿Qué es república? Lima: USMP.

Pease, H. (2010). ¿Cómo funciona el presidencialismo en el Perú? Lima: PUCP.

Sánchez, R. (2018). Hildebrandt en sus trece.

Valenzuela, A. (1996). América Latina: el presidencialismo en crisis. Pensamiento Constitucional, 3(3), 15-28. Recuperado de http://revistas.pucp.edu.pe/index.php/pensamientoconstitucional/article/ view/3340/3189

Vergara, A. (2013). Ciudadanos sin república. Lima: Planeta.

Zavaleta, M. (2014). Coaliciones de independientes. Las reglas no escritas de la política electoral. Lima: IEP. 